Annals of International Medical and Dental Research

E-ISSN: 2395-2822 | P-ISSN: 2395-2814

Vol-8, Issue-1 | January-February 2022

DOI: $10.53339 /$ aimdr.2022.8.1.46

Page no- 368-378 | Section- Research Article (Surgery)

\title{
HER2 Positive Gastric and Gastroesophageal Adenocarcinoma: A Tertiary Center Experience in (NICRH) Bangladesh
}

\author{
Nabir Hossain'1, Mhafuze Ara Begum², Md. Ahsan Habib ${ }^{3}$
}

\begin{abstract}
${ }^{1}$ Associate Professor (Surgery), Department of Surgical Oncology, National Institute of Cancer Research \& Hospital (NICRH), Dhaka, Bangladesh. Email:dnabir7796@gmail.com Orcid id: 0000-0001-6092-6946 2DPM(HRD)CBHC OPERATION PLAN, DGHS, Mohakhali, Dhaka-1212, Bangladesh.

Email: drmhafuze7@gmail.com

Orcid id: 0000-0001-6092-6946

${ }^{3}$ Associate Professor (Colorectal Surgery), Department of Colorectal Surgery, Dhaka Medical College and Hospital, Dhaka, Bangladesh.

Email: drahsanhabib1306@gmail.com

Orcid id: 0000-0001-6092-6958
\end{abstract}

*Corresponding author

Received: 05 September 2021

Revised: 02 December 2021

Accepted: 12 December 2021

Published: 22 December 2021

\begin{abstract}
Background: Gastric cancer is the fourth commonest cancer worldwide. It is also recognized as the second commonest cause of cancer related death in the global perspective. Although the incidence of gastric cancer has gradually decreased over the last half of the century, it varies among the different part of the world and different ethnic group. Mortality from gastric cancer extremely high, and it is second only to lung cancer. Gastric cancer occurs more frequently in men than in women. Aim of the study: Aim of the study was to find the clinic-profile outcome HER2 Positive Gastric and Gastroesophageal Adenocarcinoma. Methods: This cross sectional study was conducted in the Department of Surgical Oncology of National Institute of Cancer, Research and Hospital, Mohakhali, Dhaka. The study period was from March, 2014 to April, 2015. A total of 80 patients were included for the study. After receiving the gastrectomy specimen, it was fixed in $10 \%$ formaldehyde. Data were compiled and necessary statistical analysis were carried out using computer based software package for social science (SPSS 16.1). Ethical clearance was taken from the ethical committee of NICRH. Results: The highest patients were from 61-70 years' age group and the lowest were from $71-80$ years. The mean age of the patients was $59.71( \pm 10.19)$ years. The female to male ratio in this study was 1: $2.48 .66(82.5 \%)$ patients were presented with anemia which was followed by $39(48.75 \%)$ cases with dehydration. Most of the tumors were located in the distal part of the stomach $(11.67 \%)$. Regarding staging $79(12.65 \%)$ patients were in the advanced stage of the disease. The correlation between HER2 overexpression and TNM staging has been tabulated below where it is shown that only Nodal (N) staging has the significant correlation with the HER2 overexpression. Conclusion: It is already mentioned that, in early history of immunohistochemistry, HER2 overexpression in case of carcinoma stomach was highly varied in different studies (from 9-92\%). But recently, it was found around $9-32 \%$, in several studies all over the world. It is necessary to conduct further studies with larger samples and long term follow-up in order to draw definite conclusions regarding the role of HER2/neu overexpression.
\end{abstract}

Keywords:- Gastric cancer, Expression, HER2, Epidermal, Prognosis.

\section{INTRODUCTION}

Cancer of the stomach and gastroesophageal junction (GEJ) constitutes a major health problem worldwide. It is the most common cancer diagnosed in men in Japan. Its incidence in the USA is, however, low.[1] The incidence of 
Annals of International Medical and Dental Research

E-ISSN: 2395-2822 | P-ISSN: 2395-2814

Vol-8, Issue-1 | January-February 2022

DOI: $10.53339 /$ aimdr.2022.8.1.46

Page no- 368-378 | Section- Research Article (Surgery)

gastric cancer is decreasing and lies between 10 and 15 new cases per 100,000 populations per year in most Western countries. Peak age is between 60 and 80 years. Whereas distal gastric cancers account for the overall decrease in gastric cancer, tumors in the proximal stomach (cardia and GEJ) are on the rise. [2,3] In Bangladesh, the incidence of gastric cancer is low, compared to the high-risk areas such as Japan, Korea, and China. Gastric cancer is often diagnosed in a locally advanced or metastatic stage when the tumor is unresectable. The current chemotherapeutic agents do not offer a substantial response with response rates varying from 10 to $60 \%$, and thus, the survival of patients on palliative chemotherapy remains poor. [4] Hence, there has been a tremendous effort for the search of new therapeutic strategies and targets. One such strategy is targeting the human epidermal growth factor receptor 2 (HER2), also known as HER-neu. The HER2 gene is a member of the epidermal growth factor receptor family. HER2 is encoded by a gene located on chromosome 17q21.[5] The HER2 gene is located adjacent to the topoisomerase IIa genes. It encodes for the 185-kDa receptor, HER2, which has an extracellular ligand-binding domain, transmembrane and intracellular domain with tyrosine kinase activity. HER2 does not bind to any known ligand, but it forms a heterodimer with other members of the HER family and initiates a cascade of reactions that can influence many aspects of tumor cell biology, including cell prolife action, apoptosis, adhesion, migration, and differentiation. In carcinomas, HER2 acts as an oncogene. [6] Highlevel amplification of the gene induces protein overexpression in the cellular membrane and can be picked up by the fluorescence in situ hybridization (FISH) test. HER2 has been found overexpressed in a number of neoplasm, the most studied being breast cancer where overexpression is reported in 10 to $34 \%$ of cases.[7] Trastuzumab, a fully humanized monoclonal antibody, targets the extracellular domain of the HER2 receptor and thereby prevents its activation. Trastuzumab is already widely used for the treatment of HER2-positive breast cancer and has shown to improve survival in patients with HER-positive breast cancer. ${ }^{[8]}$ With increasing understanding of the molecular biology of HER2, and the availability of genomics and proteomics analyses, it has now been recognized that HER2 is implicated in other severe forms of cancer, notably gastric cancer. Therefore, the aims of this review are to provide an update on our knowledge of HER2 in the context of gastric cancer and to describe the clinical trials that have examined the potential of using trastuzumab to treat this disease, such as the Trastuzumab for Gastric Cancer (ToGA) trial, [9] or are currently underway. HER2 is a protooncogene encoded by ERBB2 on chromosome 17. It is a member of the HER family and consists of four plasma membrane-bound receptor tyrosine kinases that transmit extracellular signals to initiate cellular signaling pathways via mitogen-activated protein kinase, phosphoinositide 3-kinase, phospholipase $C$, protein kinase $C$, and signal transducer and activator of transcription. Following early studies, $[10,11,12]$ it has now become clear that HER2 is expressed in many tissues, including the breast, gastrointestinal tract, kidney, and heart. Its major role in these tissues is to promote cell proliferation and suppress apoptosis, which may facilitate excessive/uncontrolled cell growth and 
Annals of International Medical and Dental Research

E-ISSN: 2395-2822 | P-ISSN: 2395-2814

Vol-8, Issue-1 | January-February 2022

DOI: $10.53339 /$ aimdr.2022.8.1.46

Page no- 368-378 | Section- Research Article (Surgery)

tumorigenesis.[13,14,15] This has encouraged investigation of its antitumor activity in patients with HER2- positive gastric adenocarcinomas. The expression of HER2 in gastric cancer remains low. HER2 overexpression has been reported in 9.5 to $12 \%$ of gastric cancer and 24 to $25 \%$ GEJ cancer in various studies.116,17] In a recent trial, Trastuzumab for GAstric cancer (ToGA), patients assigned to the trastuzumab treatment protocol showed an improved overall survival over those not receiving this treatment. Median overall survival was reported as 13.8 months [95\% confidence interval (CI) 12-16] in those assigned to trastuzumab plus chemotherapy (n = 294) compared with 11.1 months (10-13) in those assigned to chemotherapy alone $(n=290)$ (hazard ratio $0.74 ; 95 \%$ CI $0.60-0.91 ; \mathrm{p}=$ 0.0046).[18] Although data regarding frequency of HER2 expression have been reported from several countries across the globe, published data on Indian population are very limited.19,20] We hereby present our data on HER2 expression in gastric and GEJ cancer (Siewert type III). HER2 is a proto-oncogene encoded by ERBB2 on chromosome 17. It is a member of the HER family and consists of four plasma membrane-bound receptor tyrosine kinases that transmit extracellular signals to initiate cellular signaling pathways via mitogen-activated protein kinase, phosphoinositide 3-kinase, phospholipase C, protein kinase $C$, and signal transducer and activator of transcription. Following early studies, $[10,11,12]$ it has now become clear that HER2 is expressed in many tissues, including the breast, gastrointestinal tract, kidney, and heart. Its major role in these tissues is to promote cell proliferation and suppress apoptosis, which may facilitate excessive/uncontrolled cell growth and tumorigenesis. [13,14,15,16,17] Aim of the study was to find the clinic-profile outcome HER2 Positive Gastric and Gastroesophageal Adenocarcinoma.

\section{MATERIAL AND METHODS}

This cross sectional study was conducted in the Department of Surgical Oncology of National Institute of Cancer, Research and Hospital, Mohakhali, Dhaka. The study period was from March, 2014 to April, 2015. A total of 80 patients were included for the study according to following inclusion and exclusion criteria. After receiving the gastrectomy specimen, it was fixed in $10 \%$ formaldehyde. After fixation a systemic gross examination was performed and adequate tissue sections were submitted and embedded in paraffin. Then histologic sections with 3-5 micron thickness were obtained from paraffin blocks and was initially stained with hematoxylin eosin for histological assessment. $\mathrm{H}$ \& $\mathrm{E}$ stained slides were evaluated for histological examination (tumor classification, grading, and depth of tumor, nodal stage and lymphovascular invasion). Gastric cancer was classified histopathologically according to Lauren's system (Intestinal, diffuse and mixed) and on the grading (well differentiated, moderately differentiated and poorly differentiated). Only the gastric adenocarcinomas, diagnosed in hematoxylin and eosin sections were selected for immunohistochemical examination. Endogenous peroxidase activity was removed by being kept in 3\% hydrogen peroxide. Finally, the sections were counterstained with Mayers hematoxylin. Data were compiled and necessary statistical analysis were carried out using computer based software package for 
Annals of International Medical and Dental Research

E-ISSN: 2395-2822 | P-ISSN: 2395-2814

Vol-8, Issue-1 | January-February 2022

DOI: $10.53339 /$ aimdr.2022.8.1.46

Page no- 368-378 | Section- Research Article (Surgery)

social science (SPSS 16.1). Ethical clearance was taken from the ethical committee of NICRH.

\section{Inclusion Criteria}

- Patients with any age, sex, stage having histopathologically confirmed carcinoma stomach.

\section{Exclusion Criteria}

- Previous history of gastric surgery.

- Patients with history of radiotherapy.

\section{RESULTS}

The highest patients were from 61-70 years' age group and the lowest were from 21-30 years. Among the 165 respondents the maximum number of patients achieved primary education; 50 (30.30\%) which was followed by the number of patients with illiteracy. According to symptoms 124(75.15\%) were from abdominal pain which was the height number and only one patient had no pain. $101(61.21 \%)$ were from 18-24.9 (Normal) BMI and no one from 25-29 (Overweight) and $\geq 30$ (Obese). 124(75.15\%) patients were scored $0, \quad 21(12.73 \%)$ were scored $+1, \quad 18(10.91 \%)$ patients were scored +3 and 2(1.21\%) patients were scored +2 [Table 1]. Out of 165 patients of study 118 were male $(71.25 \%)$ and 47 were female $(28.75 \%)$ [Figure 1]. The income of majority of respondents were 10,000-20,000 BDT that means maximum patients came from middle class status. The housing status in majority of patients were semi-pacca. The sanitation status was acceptable in 143(86.67\%) patients [Table 2]. The sign gradual increase with increasing of sign like cervical lymphnode, abdominal lump, dehydration and anamia [Figure 2]. [Table 3] shows the tumor morphology; firstly, location $41(14.63 \%)$ were from proximal with HER2 positivity 6, 124 (11.29) were from distal with HER2 positivity 14; secondly, staging zero percentage were from early and 163(12.27\%) were from advanced with 20 HER2 positivity. And it shows also the grading and Laurence type. According to [Table 4] results of HER2 assessment; 140 patients IHC scoring frequently $0,+1,+2,+3$ (IHC) and 25 patients had HER2 amplified \& HER2 not amplified.

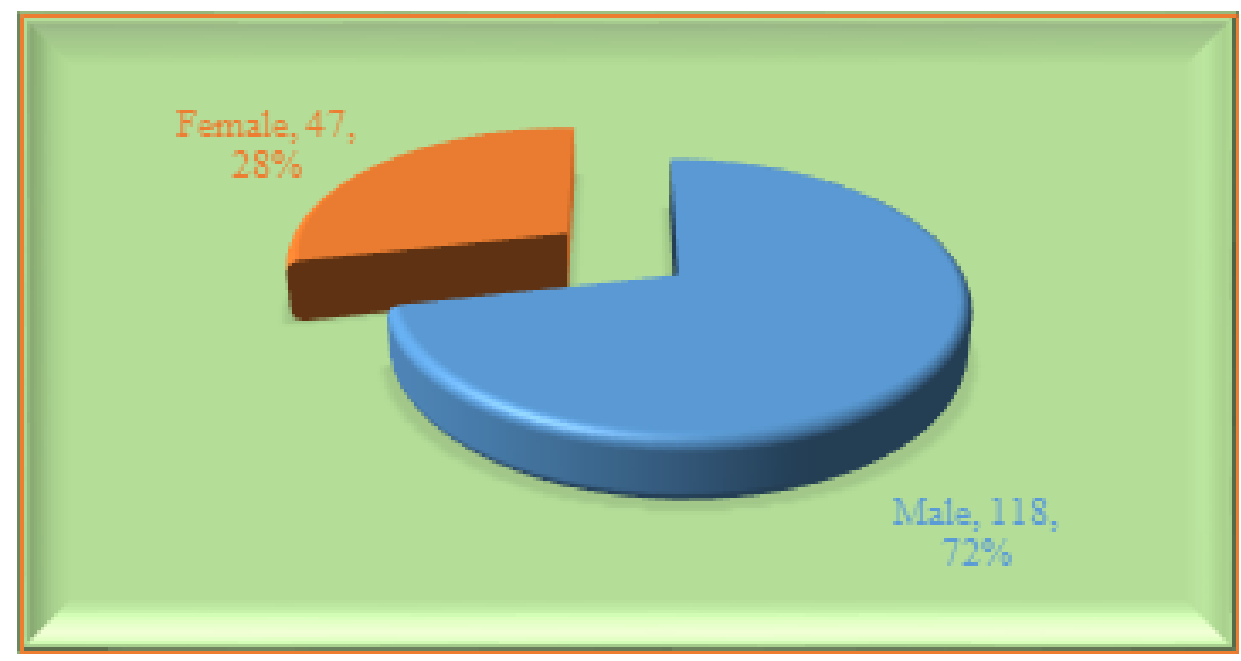

Figure 1: Shows the sex distribution of the patients $(\mathrm{N}=165)$. 
Annals of International Medical and Dental Research E-ISSN: 2395-2822 | P-ISSN: 2395-2814

Vol-8, Issue-1 | January-February 2022

DOI: $10.53339 /$ aimdr.2022.8.1.46

Page no- 368-378 | Section- Research Article (Surgery)

Table 1: Distribution of Age, Educational Status, Symptoms, BMI, HER-2 positivity of the patients $(\mathrm{N}=165)$.

\begin{tabular}{|c|c|c|}
\hline Characteristics & Frequency & Percentage (\%) \\
\hline \multicolumn{3}{|l|}{ Age Distribution } \\
\hline $21-30$ & 5 & 3.03 \\
\hline $31-40$ & 20 & 12.12 \\
\hline $41-50$ & 35 & 21.21 \\
\hline $51-60$ & 40 & 24.24 \\
\hline $61-70$ & 50 & 30.30 \\
\hline $71-80$ & 15 & 9.09 \\
\hline Total & 165 & 100.00 \\
\hline \multicolumn{3}{|l|}{ Educational Status } \\
\hline Illiterate & 50 & 30.30 \\
\hline Primary & 58 & 35.15 \\
\hline SSC & 31 & 18.79 \\
\hline HSC & 16 & 9.70 \\
\hline Graduation \& above & 10 & 6.06 \\
\hline Total & 165 & 100.00 \\
\hline \multicolumn{3}{|l|}{ Symptoms } \\
\hline Weight loss & 39 & 23.64 \\
\hline Anorexia & 70 & 42.42 \\
\hline Abdominal pain & 124 & 75.15 \\
\hline Weakness. & 60 & 36.36 \\
\hline Vomiting & 97 & 58.79 \\
\hline Dyspepsia & 27 & 16.36 \\
\hline Dysphagia & 29 & 17.58 \\
\hline Melaena & 19 & 11.52 \\
\hline Lump & 17 & 10.30 \\
\hline Painless & 1 & 0.61 \\
\hline Haematemesis & 4 & 2.42 \\
\hline \multicolumn{3}{|l|}{ Body Mass Index } \\
\hline$<18$ (underweight) & 64 & 38.79 \\
\hline 18-24.9 (Normal) & 101 & 61.21 \\
\hline 25-29 (Overweight) & 0 & 0.00 \\
\hline$\geq 30$ (Obese) & 0 & 0.00 \\
\hline Total & 165 & 100.00 \\
\hline \multicolumn{3}{|l|}{ HER-2 positivity } \\
\hline $3+$ & 18 & 10.91 \\
\hline $2+$ & 2 & 1.21 \\
\hline
\end{tabular}


Annals of International Medical and Dental Research

E-ISSN: 2395-2822 | P-ISSN: 2395-2814

Vol-8, Issue-1 | January-February 2022

DOI: $10.53339 /$ aimdr.2022.8.1.46

Page no- 368-378 | Section- Research Article (Surgery)

\begin{tabular}{|l|l|l|}
\hline $1+$ & 21 & 12.73 \\
\hline 0 & 124 & 75.15 \\
\hline Total & 165 & 100.00 \\
\hline
\end{tabular}

Table 2: Distribution of the Patients by Socio-economic status $(\mathrm{n}=165)$

\begin{tabular}{|l|l|l|}
\hline Characteristics & Frequency & Percentage (\%) \\
\hline Income (Tk) & 62 & 37.58 \\
\hline$<10000$ & 76 & 46.06 \\
\hline $10000-20000$ & 27 & 16.36 \\
\hline$>20000$ & 33 & 20.00 \\
\hline Housing & 109 & 66.06 \\
\hline Kancha & 23 & 13.94 \\
\hline Semi-Pacca (Tin shade) & \multicolumn{2}{|l|}{} \\
\hline Pacca & 22 & 13.33 \\
\hline Sanitation & 143 & 86.67 \\
\hline Poor & \multicolumn{2}{|l|}{} \\
\hline Acceptable &
\end{tabular}

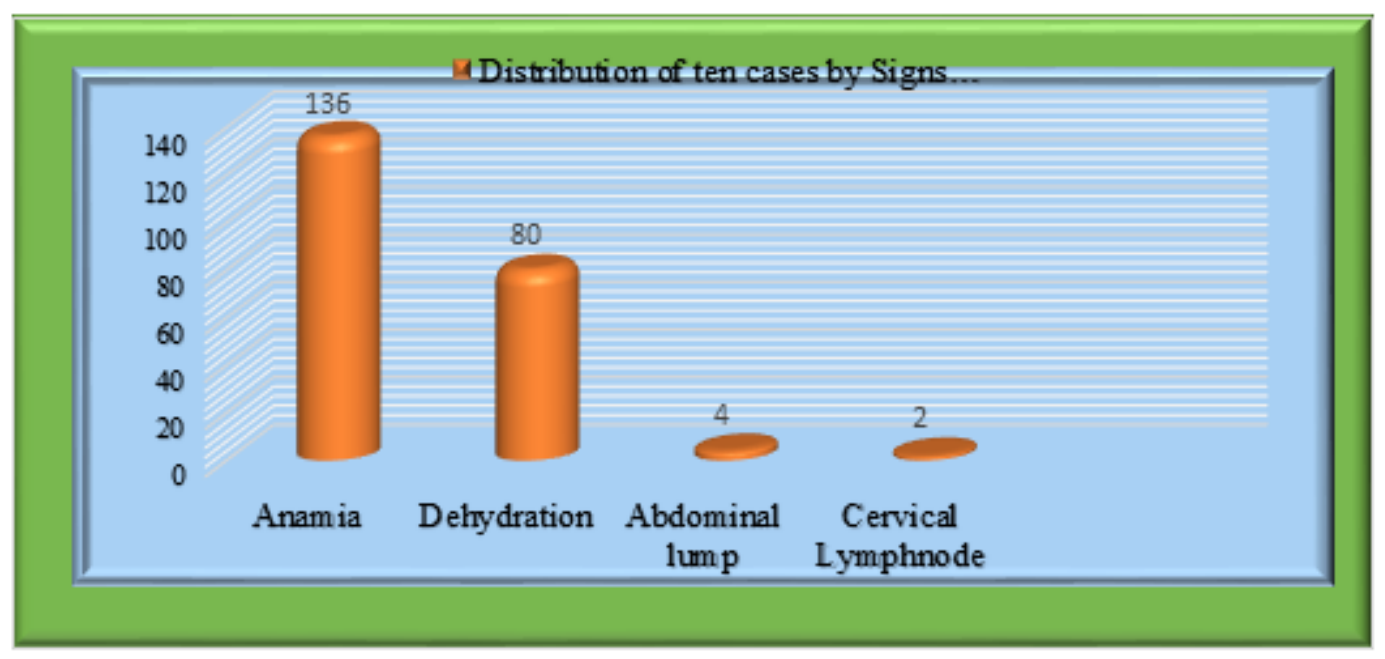

Figure 2: Shows distribution of cases by sign $(n=165)$.

Table 3: Distribution of correlation of patients with tumor morphology, frequency and HER2 positivity $(\mathrm{n}=165)$

\begin{tabular}{|l|l|l|l|}
\hline Tumor morphology & Frequency & HER 2 Positive & Percentage \\
\hline Location & 41 & 6 & 14.63 \\
\hline Proximal & 124 & 14 & 11.29 \\
\hline Distal & \multicolumn{3}{l|}{} \\
\hline Staging & \multicolumn{3}{|l|}{} \\
\hline
\end{tabular}


Annals of International Medical and Dental Research

E-ISSN: 2395-2822 | P-ISSN: 2395-2814

Vol-8, Issue-1 | January-February 2022

DOI: $10.53339 /$ aimdr.2022.8.1.46

Page no- 368-378 | Section- Research Article (Surgery)

\begin{tabular}{|l|l|l|l|}
\hline Early & 2 & 0 & 0.00 \\
\hline Advanced & 163 & 20 & 12.27 \\
\hline Grading & \multicolumn{4}{l|}{} \\
\hline Well to Moderately differentiated & 91 & 14 & 15.38 \\
\hline Poorly differentiated & 74 & 6 & 8.11 \\
\hline Laurence type & 93 & 16 & 17.20 \\
\hline Intestinal & 93 & 4 & 5.56 \\
\hline Diffuse & 72 & 4 &
\end{tabular}

Table 4: Results of HER2 assessment.

\begin{tabular}{|l|l|l|}
\hline IHC score $\mathbf{( n = 1 4 0 )}$ & Frequency & Percentage (\%) \\
\hline 0 & 29 & 20.71 \\
\hline+1 & 65 & 46.43 \\
\hline+2 & 25 & 17.86 \\
\hline+3 & 21 & 15.00 \\
\hline FISH $(\mathrm{n}=25)$ & Frequency & Percentage $(\%)$ \\
\hline HER2 amplified & 9 & 36.00 \\
\hline HER2 Not amplified & 16 & 64.00 \\
\hline
\end{tabular}

\section{DISCUSSION}

This study was undertaken in a tertiary care referral hospital of Bangladesh to assess the HER2 status in patients with gastric and GEJ cancer. A lack of interest in pursuing HER2 status in advanced gastric cancer is possibly because trastuzumab is still out of reach of a large majority of Bangladeshi patients who do not have any kind of medical insurance to cover the cost of such treatment. Similar sentiment is shared by our neighboring country China, which estimated an annual increase in fiscal expenditures to be approximately $\$ 1$ billion rendering the treatment not cost-effective.[21] Nevertheless, this study brings out certain facts discussed as follows that need to be confirmed on a larger subset of patients in future studies. The HER2 is overexpressed in a minority of patients with gastric and GEJ cancer ranging from 2 to 45
\%.[22] Overexpression of HER2 protein in gastric cancer using IHC was first described in 1986.[23] In a Japanese series, HER2 overexpression was found in 23 and $27 \%$ by IHC and FISH, respectively, in 200 resected specimens and $16 \%$ in a Korean series. [24,25] The HER2 overexpression in our study was $18(10.91 \%)$ of IHC score $+3,2(1.21 \%)$ of IHC score +2 and $124(75.15 \%)$ of IHC score +1 . We included patients with IHC score $2+$ and $3+$. FISH analysis could not be carried out in HER2 $2+$ cases due to economic constraints, and hence, our HER2 positivity rate may actually be lower. HER2 overexpression has been reported to be associated with advanced stage and poor overall survival in breast cancer. However, conflicting data are available for the same in gastric cancer. A Chinese study recently reported HER2 positivity to be an independent poor prognostic factor $(p=0.042)$ 
Annals of International Medical and Dental Research

E-ISSN: 2395-2822 | P-ISSN: 2395-2814

Vol-8, Issue-1 | January-February 2022

DOI: $10.53339 /$ aimdr.2022.8.1.46

Page no- 368-378 | Section- Research Article (Surgery)

for recurrence in differentiated gastric cancers. [26] In another study involving 260 gastric cancer samples, HER2 expression was an independent prognostic factor, and the intensity of HER2 staining correlated with tumor size, serosal invasion, and lymph node metastases.[27] Nakajima et al. stated that even in early-stage tumors, HER2 overexpression is the second poorest prognostic variable after nodal status. [28] Park et al. from Korea found age, tumor-node-metastasis (TNM) stage and amplification of HER2 to be independently related to survival by multivariate analysis in their study of 182 gastric cancer patients who underwent curative surgery. Intestinal-type cancers also exhibited higher rates of HER2 amplification than did diffuse-type cancers $(p<0.05) .{ }^{[25]}$ On the contrary, recent studies involving a large cohort of patients found on association of HER2 overexpression with patient survival or TNM stage.[29,30] No association was found between HER2 overexpression and age, gender, stage and grade of tumor in our study. The DFS was also not different in the HER2-positive vs. HER2negative patients. However, this could be due to the short follow-up of just 2 years and a small subset of patients. HER2 overexpression appears to be associated with intestinal-type gastric cancer, [30] and therefore, sub classification of gastric adenocarcinomas as intestinal or diffuse type may have implications for therapy. The specific reasons for the overexpression of HER2 in intestinaltype gastric carcinomas are complex and demand further study. A correlation has been drawn to breast cancer wherein HER2 gene amplification is a common feature in invasive ductal carcinomas and an uncommon feature in lobular carcinomas. In gastric cancer, HER2 gene amplification is reportedly inversely associated with E-cadherin mutations, [31] the latter are associated with diffuse gastric and lobular invasive breast cancers but rare in intestinal gastric and ductal invasive breast cancers. [32] It is imperative to diagnose the HER2-positive cases with accuracy because it opens a new channel of treatment with trastuzumab. It has been reported that HER2 expression is different in gastric and breast cancers. Gastric cancer shows considerable intratumoral heterogeneticity, and positivity rates may differ in samples taken from resected specimen compared to those taken as a biopsy.[29] Thus, pathologists worldwide argue for a gastric cancer scoring system that is slightly different from the scoring system currently being used for breast cancer. [33] An understanding of the scoring modifications is required for proper stratification of gastric cancer patients for treatment. An interesting study published very recently examined HER2 overexpression by IHC and HER2 gene amplification by FISH in 169 patients (99 gastric adenocarcinomas, [30] 70 GEJ carcinomas) using scoring schemes proposed by both the American Society of Clinical Oncology/College of American Pathologists (ASCO/CAP) and the those published by the ToGA trial. Overall, 19 adenocarcinomas were HER2 positive, defined as either a HER2/CEP17 ratio $>2.2$ and/or a $3+$ HER2 IHC score with either the ASCO/CAP or ToGA scoring schemes. Of the 19 HER2positive adenocarcinomas, eight (42\%) exhibited a characteristic strongly intense basolateral membranous staining pattern that would be interpreted as negative $(1+)$ using the accepted ASCO/CAP scoring scheme for HER2 assessment in breast carcinoma, but 
Annals of International Medical and Dental Research

E-ISSN: 2395-2822 | P-ISSN: 2395-2814

Vol-8, Issue-1 | January-February 2022

DOI: $10.53339 /$ aimdr.2022.8.1.46

Page no- 368-378 | Section- Research Article (Surgery)

were correctly labeled as $3+$ positive using the proposed ToGA scoring scheme. Of the 19 HER2-positive adenocarcinomas, eight (42\%) demonstrated heterogeneous HER2 protein expression by IHC. The authors cautioned that a characteristic basolateral membranous pattern (often heterogeneous) of HER2 expression was observed in both gastric and GEJ adenocarcinomas rendering routine evaluation of HER2 status on small tissue samples challenging. It is important that pathologists and diagnostic laboratories learn and use the modified criteria for assessing HER2 status in gastric/GEJ cancer because a large number of new specimens will need to be tested for HER2 status by both IHC and FISH in the days to come as trastuzumab has now been approved by the Food and Drug Administration for use in metastatic gastric and GEJ adenocarcinoma.[34]

\section{Limitations of the study}

The present study had few limitations such as this study was conducted in a single hospital and had a small sample size that may not reflect the whole scenario.

\section{CONCLUSIONS}

We only found a relationship between protein expression with age and lymph node metastasis which were found statistically significant. Interestingly, there were multiple important variables that were correlated in this study with the HER2 overexpression. These variables were sex, tumor site, distant metastasis, Laurence histological classification. It is already mentioned that, in early history of immunohistochemistry, HER2 overexpression in case of carcinoma stomach was highly varied in different studies (from 9-92\%). But recently, it was found around $9-32 \%$, in several studies all over the world. It is necessary to conduct further studies with larger samples and long term follow-up in order to draw definite conclusions regarding the role of HER2/neu overexpression as an independent prognostic factor. Study should be multi-center basis. Multi-disciplinary approach should be mandatory to get a good outcome where the surgical oncologists, Thoracic surgeon, Gastroenterologists, Histopathologists, Geneticists are included. FISH procedures should be available for equivocal cases in every center. The experts involved in immunohistochemistry should go through continuous training.

\section{REFERENCES}

1. Waterman BR, Belmont PJ Jr, Schoenfeld AJ. Low back pain in the United States: incidence and risk factors for presentation in the emergency setting. Spine J. 2012;12(1):63-70. doi: 10.1016/j.spinee.2011.09.002.

2. Krejs GJ. Gastric cancer: epidemiology and risk factors. Dig Dis. 2010;28(4-5):600-3. doi: 10.1159/000320277.

3. Vial M, Grande L, Pera M. Epidemiology of adenocarcinoma of the esophagus, gastric cardia, and upper gastric third. Recent Results Cancer Res. 2010;182:1-17. doi: 10.1007/978-3-540-70579-6_1. 
Annals of International Medical and Dental Research

E-ISSN: 2395-2822 | P-ISSN: 2395-2814

Vol-8, Issue-1 | January-February 2022

DOI: $10.53339 /$ aimdr.2022.8.1.46

Page no- 368-378 | Section- Research Article (Surgery)

4. Sastre J, Garcia-Saenz JA, Diaz-Rubio E. Chemotherapy for gastric cancer. World J Gastroenterol. 2006;12(2):204-13. doi: 10.3748/wjg.v12.i2.204.

5. Akiyama T, Sudo C, Ogawara H, Toyoshima K, Yamamoto T. The product of the human c-erbB-2 gene: a 185-kilodalton glycoprotein with tyrosine kinase activity. Science. 1986;232(4758):1644-6. doi: 10.1126/science.3012781.

6. Slamon DJ, Godolphin W, Jones LA, Holt JA, Wong SG, Keith DE, et al. Studies of the HER-2/neu protooncogene in human breast and ovarian cancer. Science. 1989;244(4905):707-12. doi: 10.1126/science. 2470152.

7. Kaptain S, Tan LK, Chen B. Her-2/neu and breast cancer. Diagn Mol Pathol. 2001;10(3):139-52. doi: 10.1097/00019606-200109000-00001.

8. Smith I, Procter M, Gelber RD, Guillaume S, Feyereislova A, Dowsett M, et al; HERA study team. 2-year follow-up of trastuzumab after adjuvant chemotherapy in HER2-positive breast cancer: a randomised controlled trial. Lancet. 2007;369(9555):29-36. doi: 10.1016/S01406736(07)60028-2.

9. Bang YJ, Van Cutsem E, Feyereislova A, Chung HC, Shen L, Sawaki A, Lordick F, et al; ToGA Trial Investigators. Trastuzumab in combination with chemotherapy versus chemotherapy alone for treatment of HER2-positive advanced gastric or gastro-oesophageal junction cancer (ToGA): a phase 3, open-label, randomised controlled trial. Lancet. 2010;376(9742):687-97. doi: 10.1016/S01406736(10)61121-X.

10. Coussens L, Yang-Feng TL, Liao YC, Chen E, Gray A, McGrath J, et al. Tyrosine kinase receptor with extensive homology to EGF receptor shares chromosomal location with neu oncogene. Science. 1985 Dec 6;230(4730):1132-9. doi: 10.1126/science.2999974.

11. Olayioye MA. Update on HER-2 as a target for cancer therapy: intracellular signaling pathways of ErbB2/HER-2 and family members. Breast Cancer Res. 2001;3(6):385-9. doi: 10.1186/bcr327.

12. Yamamoto $T$, Ikawa $S$, Akiyama $T$, Semba K, Nomura N, Miyajima N, et al. Similarity of protein encoded by the human c-erb-B-2 gene to epidermal growth factor receptor. Nature. 1986;319(6050):230-4. doi: 10.1038/319230a0.
13. Neve RM, Lane HA, Hynes NE. The role of overexpressed HER2 in transformation. Ann Oncol. 2001;12 Suppl 1:S9-13. doi: 10.1093/annonc/12.suppl_1.s9.

14. Ménard S, Pupa SM, Campiglio M, Tagliabue E. Biologic and therapeutic role of HER2 in cancer. Oncogene. 2003;22(42):6570-8. doi: 10.1038/sj.onc.1206779.

15. Rubin I, Yarden Y. The basic biology of HER2. Ann Oncol. 2001;12 (Suppl 1):S3-8. doi: 10.1093/annonc/12.suppl_1.s3.

16. Gravalos C, Jimeno A. HER2 in gastric cancer: a new prognostic factor and a novel therapeutic target. Ann Oncol. 2008;19(9):1523-9. doi: 10.1093/annonc/mdn169.

17. Tanner M, Hollmén M, Junttila TT, Kapanen AI, Tommola S, Soini Y, et al. Amplification of HER-2 in gastric carcinoma: association with Topoisomerase Ilalpha gene amplification, intestinal type, poor prognosis and sensitivity to trastuzumab. Ann Oncol. 2005;16(2):273-8. doi: 10.1093/annonc/mdi064.

18. Bang YJ, Van Cutsem E, Feyereislova A, Chung HC, Shen L, Sawaki A, et al; ToGA Trial Investigators. Trastuzumab in combination with chemotherapy versus chemotherapy alone for treatment of HER2positive advanced gastric or gastro-oesophageal junction cancer (ToGA): a phase 3, open-label, randomised controlled trial. Lancet. 2010;376(9742):687-97. doi: 10.1016/S01406736(10)61121-X.

19. Sekaran A, Kandagaddala RS, Darisetty S, Lakhtakia $S$, Ayyagari S, Rao GV, et al. HER2 expression in gastric cancer in Indian population--an immunohistochemistry and fluorescence in situ hybridization study. Indian J Gastroenterol. 2012;31(3):106-10. doi: 10.1007/s12664-012-0214-0.

20. Patil PS, Mehta SA, Mohandas KM. Over-expression of HER2 in Indian patients with gastric cancer. Indian J Gastroenterol. 2013;32(5):350. doi: 10.1007/s12664-012-0279-9.

21. Wu B, Ye M, Chen H, Shen JF. Costs of trastuzumab in combination with chemotherapy for HER2positive advanced gastric or gastroesophageal junction cancer: an economic evaluation in the Chinese context. Clin Ther. 2012;34(2):468-79. doi: 10.1016/j.clinthera.2012.01.012. 
Annals of International Medical and Dental Research

E-ISSN: 2395-2822 | P-ISSN: 2395-2814

Vol-8, Issue-1 | January-February 2022

DOI: $10.53339 /$ aimdr.2022.8.1.46

Page no- 368-378 | Section- Research Article (Surgery)

22. Moelans CB, van Diest PJ, Milne AN, Offerhaus GJ. Her-2/neu testing and therapy in gastroesophageal adenocarcinoma. Patholog Res Int. 2010;2011:674182. doi: 10.4061/2011/674182.

23. Sakai K, Mori S, Kawamoto T, Taniguchi S, Kobori O, Morioka Y, et al. Expression of epidermal growth factor receptors on normal human gastric epithelia and gastric carcinomas. J Natl Cancer Inst. 1986;77(5):1047-52.

24. Yano T, Doi T, Ohtsu A, Boku N, Hashizume K, Nakanishi $M$, et al. Comparison of HER2 gene amplification assessed by fluorescence in situ hybridization and HER2 protein expression assessed by immunohistochemistry in gastric cancer. Oncol Rep. 2006;15(1):65-71.

25. Park DI, Yun JW, Park JH, Oh SJ, Kim HJ, Cho YK, et al. HER-2/neu amplification is an independent prognostic factor in gastric cancer. Dig Dis Sci. 2006;51(8):1371-9. doi: 10.1007/s10620-005-9057-1.

26. Kim KC, Koh YW, Chang HM, Kim TH, Yook JH, Kim BS, et al. Evaluation of HER2 protein expression in gastric carcinomas: comparative analysis of 1,414 cases of whole-tissue sections and 595 cases of tissue microarrays. Ann Surg Oncol. 2011;18(10):2833-40. doi: 10.1245/s10434-011-1695-2.

27. Yonemura Y, Ninomiya I, Yamaguchi A, Fushida S, Kimura H, Ohoyama $S$, et al. Evaluation of immunoreactivity for erbB-2 protein as a marker of poor short term prognosis in gastric cancer. Cancer Res. 1991;51(3):1034-8.

28. Nakajima M, Sawada H, Yamada Y, Watanabe A, Tatsumi M, Yamashita J, et al. The prognostic significance of amplification and overexpression of c-met and c-erb B-2 in human gastric carcinomas. Cancer. 1999;85(9):1894-902. doi: 10.1002/(sici)10970142(19990501)85:9<1894::aid-cncr3>3.0.co;2-j.

29. Grabsch H, Sivakumar S, Gray S, Gabbert HE, Müller W. HER2 expression in gastric cancer: Rare, heterogeneous and of no prognostic value conclusions from 924 cases of two independent series. Cell Oncol. 2010;32(1-2):57-65. doi: 10.3233/CLO-2009-0497.

30. Kunz PL, Mojtahed A, Fisher GA, Ford JM, Chang DT, Balise RR, et al. HER2 expression in gastric and gastroesophageal junction adenocarcinoma in a US population: clinicopathologic analysis with proposed approach to HER2 assessment. Appl Immunohistochem Mol Morphol. 2012;20(1):13-24. doi: 10.1097/PAI.0b013e31821c821c.

31. Berx G, Becker KF, Höfler H, van Roy F. Mutations of the human E-cadherin (CDH1) gene. Hum Mutat. 1998;12(4):226-37. doi: 10.1002/(SICI)10981004(1998)12:4<226::AID-HUMU2>3.0.CO;2-D.

32. Tanner M, Hollmén M, Junttila TT, Kapanen AI, Tommola S, Soini Y, et al. Amplification of HER-2 in gastric carcinoma: association with Topoisomerase Ilalpha gene amplification, intestinal type, poor prognosis and sensitivity to trastuzumab. Ann Oncol. 2005;16(2):273-8. doi: 10.1093/annonc/mdi064.

33. Park YS, Hwang HS, Park HJ, Ryu MH, Chang HM, Yook JH, et al. Comprehensive analysis of HER2 expression and gene amplification in gastric cancers using immunohistochemistry and in situ hybridization: which scoring system should we use? Hum Pathol. 2012;43(3):413-22. doi: 10.1016/j.humpath.2011.05.019.

34. Ross JS, Mulcahy M. HER2 Testing in Gastric/Gastroesophageal Junction Adenocarcinomas: Unique Features of a Familiar Test. Gastrointest Cancer Res. 2011;4(2):62-6. doi: 10.1152/ajpcell.00650.2009.

Source of Support: Nil, Conflict of Interest: None declared 